\title{
IMPROVING LONG-TERM ADHERENCE TO SUBLINGUAL IMMUNOTHERAPY. RESULTS OF A PROACTIVE PATIENTS-CENTERED MANAGEMENT PLANNING.
}

\author{
A. Antico, MD \\ Ospedale Civile Srl - Allergy Unit - Volta Mantovana, MN, Italy
}

Corresponding Author

Dr. Andrea Antico

Servizio di Allergologia

Ospedale Civile Srl

Via Guido Tonello 5

46049 Volta Mantovana MN - Italy

E-mail: antico47@gmail.com

Fax: +390376839212

Tel: +39037683901

\section{ABSTRACT}

\section{Background}

Long-term adherence to sublingual immunr, $\iota$ $2 r_{a_{1}} v(S L I T)$ results very poor in real-life studies.

Effective actions are needed. Key point $\mathrm{J}$ any policy aimed to overcoming non-cost related barriers to medication long-term adh دrerce is to actively support patients' needs and preferences starting from shared decisions ma'ir. 5

\section{Objective}

To explore SLIT related view jiris, needs and preferences of a homogeneous group of patients.

To assess their priorit orc er and to what extent each of them could affect SLIT adherence. To found a rational $b_{a}^{-i}, \tau_{1}, r$ a proactive action-plan to support patients' needs and preferences and assess results $0 . \mathrm{SLI}$, long-term adherence.

\section{Patierts indlilethods}

Preforet. es and viewpoint of patients in treatment-related decisions and their health-related needs have been explored by structured, direct interview of 65 adult patient. The activities of the hospital outpatient clinic were rearranged to support needs and requests shared by all patients, 
and to allow tailored interventions integrating them into routine practice. Adherence to SLIT was studied on a different group of 129 patients aged 14 to 42 years and defined as number of patients who completed three years of therapy.

\section{Results}

SLIT was completed by 98 patients (76\%). Main cause of discontinuation for 31 re $n$ il :ing patients have been pregnancy $(16 \%)$, change of work residence $(19 \%)$, side-effects ( $1.0 \%$ ) , p rceived inefficacy (26\%), and non-compliance (29\%).

\section{Conclusion}

To improve adherence, it is necessary to investisrtc n?. ient-related factors to find a common ground to take actions aimed to remove barrif $\left.\mathrm{rS}_{\mathrm{L}}\right)$ long-term SLIT-adherence that virtually can work for all patients, but flexible enough tc $a^{\prime} . c w_{\uparrow}$ atient-tailored interventions. The substantial differences on disease's perception bet eer patients with only allergic rhinitis and those with asthma entail the necessity of differe ttiai ad approaches. Management strategy based on shared decision making followed by proa ti se and ongoing interventions to support patients' needs and preferences proves effective t, ansure a good long-term adherence to SLIT in real-life. 
KEY WORDS: - Sublingual Immunotherapy - Rhinitis, Allergic - Asthma, Alle"gic - Pa ient Compliance - Physician-Patient Relations - Decision Making, Shared

\section{INTRODUCTION}

Allergy immunotherapy (AIT) is a valuable treatment $i^{\prime} r$ allergic respiratory diseases. Modulating the immune response, AIT can modify the natural pros "es ;ion of disease and lead to long lasting

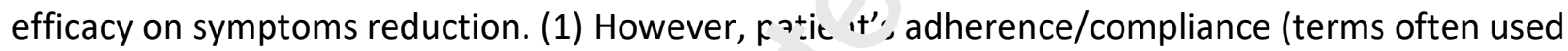
as synonymous in literature) is a crucial point as i'e regular administration of scheduled doses for a prolonged time (not inferior to three yea s) $\leqslant$ mundatory to obtain appreciable outcomes.

The subcutaneous immunotherapy $\left(\mathrm{SCl}^{7}\right)$ is the traditional method, directly managed by allergists. This should have warranted a good $\mathrm{p}$ tier t's adhesion to therapy. Nevertheless, some studies showed poor compliance in about fi'ty percent of cases, and even worse (84\%) over 3-years course. Inconvenience was tr - main cause of withdrawal. (2-4)

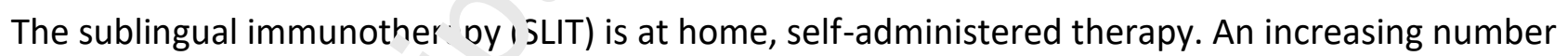
of clinical trials and met anaiyses have proved its efficacy and showed a better safety profile than subcutaneous methoc (5) In European countries SLIT is becoming the preferred delivery method. The easy of intake c.ld jonvenience should have ensured an adequate compliance.

Unlike the optin : ti previsions of a better compliance for SLIT against SCIT, post-marketing

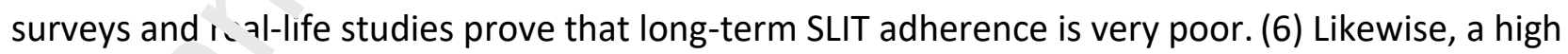
withd 'wal ra ie was observed in our hospital outpatient clinic.

Eff. $\therefore \therefore$ ᄀctions to improve adherence are needed. Studies and systematic reviews of non-costrelated barriers to medication long-term adherence (summarized/reviewed by Expert Panel of World Health Organization, RAND Corporation and on Medscape Website) have demonstrate that 
a key point of any policy aimed to strengthen adherence is to support patients' needs and preferences. (7-9)

However, each patient shows a unique cluster of reasons to adhere or not adhere. To find 1 common ground it is necessary to investigate patient-related factors by homogeneous [ rou is, who are representative of the real, customary population of users.

This information is necessary to rearrange the procedures of the outpatient clinic: $f$ or purpose to remove more substantial barriers to long-term SLIT-adherence by action-plnns that could generally work for all patients, but flexible enough to allow patient-tailored interventic. 's.

In the present study we explored needs, preferences and experiences rola : or.' to SLIT and allergy disease by homogeneous groups of our patients, assessing their releva. $\sim$ i s and priority order; then, conceived on patients' needs and preferences, we illustrate $a^{r} r$,roactive management-plan of the therapeutic program and its results on SLIT long-term adı. गrence. 


\section{PATIENTS AND METHODS}

This is an observational real-life study, aimed to describe $n \cdot \lambda_{1} m=$ nagement strategy of allergy immunotherapy, its rationale, and its outcomes on $\mathrm{SL}_{1}{ }^{\top}$ compriance. The study in based on the actual, customary patients' population, on data file an.' rr utine procedures as established by the care-pathways of the hospital outpatient clinic. '"n. .rr al Medicine and Allergy Department, Asola Hospital, Azienda Ospedaliera “C. Poma”, Mar cov , Italy)

\section{Patients' need and preferences}

Preferences and feedbacks of pati 2 r is in treatment-related decisions and their peculiar health related needs have been explored thr', ' 'gh direct interviews of 65 patients aged 18 to 48 years, mean age $31 \pm$ 9 years, $43(66 \%)$ male. To ons der if new needs were arisen over time, 34 out of them (52\%) had been on SLIT for one or : 'ore years. Forty-eight (75\%) were sensitized to pollens, $30(46 \%)$ to mites and $4(6 \%)$ to moulds , 4/tf rnaria spp). Fifteen (23\%) were undergoing two vaccines (tablets for grass; drops, single allerg $\_1, f$ sr others; pre-co-seasonal for pollens; perennial regimen for mites and Alternaria).

Forty-six (71)?' suffered from allergic rhinitis and 19 (29\%) of them had secondary symptoms of asthm: $(\leq s, \mathrm{~s}, 3)$. Eleven patients (17\%) felt asthma as the main clinical manifestation. Fortythr . na, ients (62\%) were occupied, 6 (9\%) unemployed, 6 (9\%) were housewives and 10 (15\%) were students. All patients referred to our Allergy Unit and lived in Lombardy Region. 
The interviews, hosted with colloquial style, were based on a series of written queries aimed to investigate three interacting domains: 1 . social-economic factors; 2 . patient-related factor; 3. health system and health-care team related factors.

The questionnaire was not directly administered to the patient but used by interviewer as guidance to explore needs and viewpoints of each of them, and establish together $v$ ' $u e$ :nd priority order. The relevance of each issue on the patients' perception has been i s' es ued by a visual analogical scale graded from zero to ten.

\section{SLIT support planning}

Based on interviews' results, the routine activities of outp ' ${ }^{-i}$ erıs clinic were rearranged to support needs and preference which all patients had in commr ${ }_{11}$, hut flexible enough to allow personalized interventions.

Main areas of interventions were:

1. Reengineering of the outpatient hospital clı, ic c 'ganization to support patients' needs and preference (including: practical arrangeme. ${ }^{*}$ ts avoid waste of time and bureaucratic hindrances or delays and to ensure adequate and n n. roi ig assistance starting from direct reception to counselling activities)

2. Training of team professionals to $h$.ild partnership and assist patients

3. Enhancement of patients' liter course, co-morbidities anc' cc. ${ }^{\sim}$. lications; concept of chronic inflammation and its implications)

4. Teaching allergy imm:dritherapy and training to SLIT self-management

5. Flexible patient- ${ }^{+}$illu ${ }_{-} d$ work schedule (integration of personal needs into routine practise). Shared decision- $n$. $\vee k i ı g$ process $(10,11)$ was undertaken individually with each SLIT-eligible patient to explain fur ui mentals on allergy disease and vaccine immunotherapy, and to obtain the agreemer.. $\eta$ l, eatment plan and on program of monitoring and controlling of vaccine and drug therap:- $D_{\epsilon}$ sonal request and needs were examined to be integrated into routine practice. The c'er ail SLIT supporting plan is here explained by a concise conceptual framework. (Fig 1) All patients were recalled before starting immunotherapy for educational group session aimed to reassume information given individually, recall and reinforce training on SLIT self-management, 
explain again all practical ways for direct access to the service and to receive continuative assistance also by telephonic counselling, ensure compliance with service's regulation and duties, and reinforce patients' motivation and commitment. Any request for more information or explanations was discussed in group.

\section{Adherence assessment}

Adherence was investigated in 129 patients - aged 14 to 42 years, mean ag $2 i \pm 1$. years, 91 (70\%) males. Thirty-nine patients (30\%) received two sublingual vaccines (tan'sts for grass; drops,

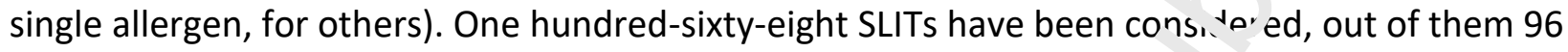
pre-co-seasonal treatments of 7 months duration per year.

The regular intake of the vaccine was directly controlled by the pers : n: iel of the allergy service. In Lombardy Region vaccines are purchased by hospital pharma!' and given out free of charge. After an educational group session, patients were invitec. $+\supset . \neg \mathrm{k} f$ the vaccine starting dose and to stay in the office waiting room for at least 30 minutes. If no significant side effects were observed, the first pack of sublingual vaccine would be filed by $a_{2}{ }^{+} e$ and delivered to each patient by the healthcare staff. Patients were recommended $\operatorname{tr}(n+$ nue daily therapy at home and to make an appointment not later than one week before $f$ nis, ing the box to receive further doses of the vaccine. At this point, one or some packs $w_{2} \mathrm{er}=\mathrm{vr}$ ided according to the next appointment, as foreseen by individual periodical contro' pro ?rams. In this way it was possible to check directly, from time to time, the regular intake of $\mathrm{tl}$ e doses and overall adherence to SLIT.

As a purpose of the present study, $t^{\prime} 1 e$ udherence to SLIT has been outlined with reference to those patients who completec three years of therapy (grass tablets and other pollens, pre-coseasonal regimen; mites an: Alt !rnaria, perennial regimen). Discontinuation reasons have been inquired by direct or telc, shor,e interview.

A written informed co 'ser $t$ to SLIT and to the present study participation was required to all patients. 


\section{RESULTS}

\section{Patient-related factors driving adherence}

All the patients who assent to vaccines immunotherar: $b c$ lieve that their disease was severe and /or doomed to a progressive worsening.

For patients with allergic rhinitis "progressive voı 'ening" referred to high degree and persistence of symptoms. They were not aware of poss $D^{\prime} \geq 0.0 .$. plications of the disease, like chronic sinusitis or asthma. Only patients with bronchial astr ma and a part of those who experienced symptoms of secondary asthma had significant ( onc rns for their health status and the risk of progression toward a chronic condition or dise bi'ıt and even the risk of life-threatening events.

All the patients who assent to . ${ }^{7 c c i n e s ~ i m m u n o t h e r a p y ~ e x p e r i e n c e d ~ a ~ n e g a t i v e ~ i m p a c t ~ o n ~ q u a l i t y ~}$ of life as well as a low contr 1 ot symptoms in spite of the therapy as prescribed by general practitioner (usually as-r sedted therapy). Concerns for continuous use of inhaled steroids and hope of dose reductio or withdrawal were an important reason to start immunotherapy for most of the patients witı, urr nchial asthma. In patients with allergic rhinitis, concerns for the prolonged use of antihistarı : $n f s$ or nasal steroids were not a strong motivation for vaccines immunotherapy. Comprehensı: $\bullet$ information about SLIT, its rationale, objectives and expected benefits, were requir $\mathcal{N}$ as a srerequisite before the definitive consent. The same could be stated for the ed. . tin. $^{+}$to the self-management and the prevention and control of possible adverse events. Concerns about the risk of SLIT adverse reaction or side-effect were not considered as a possible cause of non-adherence to immunotherapy. However, all patients deemed periodic controls, 
ranged from one month to one year, as necessary and advisable. Twenty-seven patients (39\%) thought that a specialist check-up should be planned once a year. However, a medical check every two or three months was considered optimal by most of the patients starting SLIT (76\%). A :tua.' $y$, regardless any planned check-up, all the patients assigned great relevance to the possik lity ‘o contact quickly (at least by phone) the medical staff and to have direct admittance $\mathrm{\imath}$. the allergy unit in cases of need, by-passing the hospital call-center or any waiting-list. Most of the patients believed that allergy vaccines management was a mat ${ }^{+}$r $f$ ey clusive competence to the allergists (88\%), as they supposed general practitioners c ' 'lan't have adequate knowledge and skill in immunotherapy.

\section{Adherence-related social-economic factors}

Vaccines for immunotherapy are expensive, and direct $c^{c} c^{+} s-n s^{-} \cdot d$ be a real obstacle to the acceptance and continuation of therapy. In Lombardy immunotherapy is charged by Regional Health Service, but most of the patients ( $82 \%$ ) believe tha free regimen could only moderately improve adherence, with the sole exception of $\because n n_{1}$ ir sless or in economic trouble patients. Similarly, private payments (when foreseen as coı tribution to health expenditure for periodical check-up and examination required by pro' Id د $\lrcorner$ rs) vould not have affected adherence to SLIT. The occupational status and consequent y th e necessity to obtain work permits were not considered as a major determent to $\mathrm{i} n \mathrm{~m}$ i notherapy adherence.

The distance from the allergy clini ' va, not deemed as a problem for patients live in the neighborhood, whereas patie $c$ living far off considered the distance from the allergy office as an important issue to accompl: $h \mathrm{~h}$ r quired medical controls.

The great majority of pa: ents $(80 \%)$ stressed the necessity to avoid undue waste of time (e.g. for bureaucratic requiren ent , long wait for medical control and examination and so on). Long waiting time was $\mathrm{D}_{\mathrm{u}} \mathrm{ce}$. ved by the patients in full working business as a significant interference with the daily oc 'Ir ation and activities.

\section{Healt' syst or, and health-care team factors driving adherence}

In $: \therefore r$, ntext the dialogue was mainly addressed to realize what actions should been taken to satisfy patients' expectations, to figure out the most suitable program of management and control of SLIT and allergy disease, in order to meet patients' agreement and make shared decisions. 
All the patients agreed that a well-planned and shared program of medical controls and examinations was the only way to monitor efficaciously the course of the allergic disease, to grade drug therapy, and to verify SLIT outcomes. Once again, strong emphasis was placed by most or 'he patients on the need to avoid unnecessary waste of time and substantial hindrance on ^ neiı own work and/or others daily tasks.

As reported above, comprehensive information about SLIT and expected benefits $f \mathrm{~d} l$ cation to the self-management, knowledge, prevention and control of possible adverse 1 sac ion or sideeffect were felt by all the patients as a primary necessity and a prerequisite $\iota^{r}$ tıe acceptance of SLIT and its long-lasting therapeutic program.

The value and the priority order of the main patient needs and prefert. r $s$ s have been shown on the annexed chart. (Fig 2) No significant differences on needs appı icil have been observed between patients starting SLIT or patients on therapy for a time.

\section{SLIT long-term adherence}

A whole cycle of SLIT was completed by 98 patients $(7, \%)$ Thirty-one patients (24\%) discontinued the vaccine therapy. Out of them, 5 because of ' ${ }^{2} \mathbf{r}_{\varepsilon}{ }^{\prime} \mathrm{a}^{\prime}$ 'cy (16\%), 2 children because of not welldefined family problems (6\%), 6 due to a chan se $\iota^{f}$ work residence $(19 \%), 3$ as a consequence of the persistence of local reactions (10\%), $8 \mathrm{for}$ p r r cived inefficacy (26\%), and 7 for admitted noncompliance (23\%).

Excluding substantial causes to withd aw he therapy, non-compliance to SLIT could be estimated of about $13 \%$ per cent of the entir 2 so ulation. The adherence profile is therefore comparable to the one issued in double-bline, lacebo-controlled (DBPC) trials. (6)

No difference in SLIT disror. inu; tion has been found between pre-co-seasonal (all pollens, 11 pts) and perennial (others al'. rgeı s, y pts) treatments. Immunotherapy with two vaccines (9 pts) compared to only one vac ine (22 pts) didn't result as a cause of withdrawal.

Based on the delivt. $y+$ me of each vaccine confection, occasional omissions of daily dose did not affect significan L.: t'ie regular intake of SLIT by the patients who completed the planned cycle of immunothera, $\mathrm{v}$.

Yearly -urn Il= tive rate of discontinuation has been 6, 22, 24 percent for the first, second and third yei incl ectively. 
Before the reorganization of our care pathways, discontinuation rate was an average of 25 percent in the first year, but it jumped to $56 \%$ in the second year and to $68 \%$ in the third year (a little lower if compared to other real-life studies). (6)

\section{DISCUSSION}

Non-adherence/non-compliance to allergen immunot arapy, as well as any long-term therapy, is a complex phenomenon. A consistent number of stua: ’s ind systematic reviews (summarized/ reviewed by Expert Panel of World Health Organizán nr, RAND Corporation and on Medscape Website) have been identified analyzing a wid $\leq \mathrm{ra}$. ge of variables consistently related to longterm compliance/adherence. (7-9) It is no ra'acys dear that in each action-plane to improve adherence it is essential to include pati its $_{i}$ erspective and to consider their need and preferences.

In the present study, needs and pr efer _nces on SLIT have been investigated by a homogeneous group of patients starting SLIT : $r$ on therapy for some years. Most of the results of our study are self-explanatory or easil!'-u. der: tood, but some of them deserve a short discussion. Large body of data prov that perception of disease severity threat and awareness of disease severity are both stro, $\sigma d^{\prime}$ terminants to patients' compliance. $(12,13)$ The patients who agreed with vaccines immu. $0^{+}$. erapy believed that their disease was severe and /or doomed to a progressive wor 'ning. However, only patients with bronchial asthma had substantial concerns about the pru_ression and worsening of disease and in general were afraid of significant risks for their e in rer th. For patients with allergic rhino-conjunctivitis, severity mainly referred to syr. . . $\sim n$ s (intensity, persistence, worsening over time and /or poor control by therapy) and impact on life quality, rather than to disease itself. All in all, they were not worried for their own health, neither aware of possible complications of the disease, like chronic sinusitis or asthma. 
This view /perception of the disease can affect adherence and induce untimely SLIT discontinuation. (13) When symptoms disappear patients feel better and think that also the disease has disappeared. Hence, they are not prone to a long-term, non-symptomatic ther: 1 py. Concerns for medication possible side-effect or adverse reactions and abstract worries ibot t the long-term consequences of inhaled corticosteroids are well known causes of intentı. naı . onadherence in asthma treatment. (14) These concerns seem to be a substantial m ' t' va cion for patients with allergy asthma to undertake vaccine immunotherapy, which ir pt rcei ed as a kind of steroid-sparing therapy. That might be a strength of information provided to nacients in order to improve SLIT adherence.

On the contrary, inhaled corticosteroids seem not to be a source of co1. $-\mathrm{n}$ for patients with allergic rhinitis. This dichotomy would deserve to be studied.

Lack of comprehensive information about therapy (rationale, ow; ${ }^{\circ}$ ctives, expected benefits, possible adverse-events) and inadequate education to $s \in f \cdot n$. $n n=$ gement is another well studied cause of unintentional non-adherence. (7-9) Howeve, , the sole provision of good information is a weak intervention, as a number of patients do not rec." । shat caregivers have advised, and a lot of them justify non-compliance by claiming the:' $x_{\imath} \cdot n r, t$ receive enough information. Moreover, SLIT is not a relief medication, but a long-term the apy, and its effects may not be immediately perceived by patients. Support and assistar cf intt. ventions are needed to reinforce patients' motivation. It has been proved that frec sen' and regular monitoring visits, and a firm involvement of patients on therapeutic program e ihai ce SLIT adherence. (6)

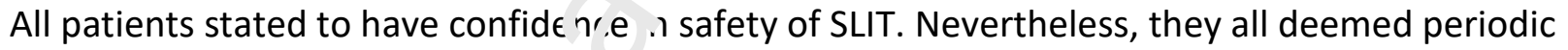
controls as necessary and adv: _ ?ble, and insisted on the possibility of a quick consultation, if only by phone, in case adverso $\epsilon$ ent . It is worth attention that patients starting SLIT preferred closer controls. We can deduc tha these patients need to strengthen their own confidence in allergy immunotherapy and i. mf dical team, and should be supported in their own motivations to confirm adherenre.

Most patients $d_{t}>m$ that the monitoring and the management of their allergy disease and of its specific thera, $v$ should not be delegated to the patient and his or her general practitioner. It may induc $\neg$ te $\mathrm{li}^{\prime}$ 'Ig of abandonment to their disease; it may generate disappointment, doubts about the $x^{+}+1, l_{c}$ effectiveness and the benefits of SLIT and, in conclusion, it may erroneously suggest that SLII might not to be necessary. All these are well known causes of non-compliance and therapy discontinuation. (7-9) 
In developed countries direct and indirect costs of therapies are not a significant cause of nonadherence, except for jobless or low-income patients. $(14,15)$ This is an outcome also of the present study. Almost all patients agreed to accomplish with a shared plan of periodic cher k-ur and examination (which will be proposed by providers), even if it entail additional direc an indirect costs. However high costs can increase the risk, as low incomes are positiv ' $v$ rc'ated to poor adherence. $(14,16)$

On the contrary, particular emphasis has been placed on the need to save t:me Th: allergic patient is usually a young man /woman in full working business or a student. ?tudents of primary or secondary school cannot live the school without parents. Undue waste nf time (long waiting for medical examinations, bureaucratic delays and problems, poor org n $^{\text {i-ation }}$ of medical services, trouble to make contact with allergy unit staff, and so on) a ?r significantly interfere with their own job and/or daily tasks. As a matter of fact, retirees anı' natients who can profit of family members' support show much better compliance than $\mathrm{p}_{\mathrm{c}}{ }^{+} \mathrm{e}_{\mathrm{i}}{ }^{+} s^{\prime}$ sho are working. (17) As stated above, the thorough knowledge of need anc requests of our patients was necessary for reengineer the procedures of the outpatient clinics bv ?ut ing in place action-plans aimed to overcome the barriers that are most important $+r \mathrm{I} ' \mathrm{~T}$.ong-term adherence and all patients have in common.

Shared decision-making (SDM) is a key poir $\mathrm{r}, \boldsymbol{i}$ su porting plan. $(10,11)$ SDM defines a consultation process aimed to establish $¥$ th rapeutic alliance between the physician and patient. (SDM is a locution which has replacec the term concordance, formerly more used in literature. It can be considered a synonymous if ic.icordance process). $(18,19)$ SDM is not a further variation of the concept of compliance/. Jherence. It refers to a work strategy to involve patients in the decision-making procedıre ind $\mathrm{n}$ the choices related to therapy and disease management. The physician and the patier. 'becume partners in the therapeutic program.

For an effective and si rce sful cooperation, the physician and the patient shall establish a genuine relationship, their $\sim s p$ ctive viewpoints and needs shall be able to be confronted, and decisions shall be shared. ' ' is necessary to resort to a structured communication to explore the patient's knowledge $a_{1}{ }^{+}$perception of disease, his/her expectations and concerns and all matters which might $: f f e c: r$ is/her adherence. Health care providers shall feel responsible for providing ex! - nti e information, make sure that the patient has understood all the issues, and the prospective barriers to adherence have been clearly discussed in order to overcome them. 
SDM is also synonymous with patient-centred care. Patient's autonomy in decision-making must be respected, and primacy of the patient's decisions acknowledged. This is the cornerstone of SDM. Any distortion or stretch to obtain an agreement should be carefully avoided. Most $n$ atit. 'ts want to have clear information about the advice or necessity of long-term therapy and consequently discuss and make decisions in agreement with the physician. In most $f$ tri - case it might be relatively easy to encourage and implement the partnership on decision $r$ ra ing process, but it is also easy to influence patients taking advantage of the doctor's author ' $v$ tr address them actually to own choices and preferences. It is even more true for patients $w_{1}$, cumpletely rely on doctors' decisions. This deceptive way to relate to the patients will ent iı in r.lany cases the decline of adherence over time. This will happen even more with AIT $\preccurlyeq$ $=$ use this treatment does not replace already existing drug therapy.

However SMD (as pointed by the summary guide of England $\mathrm{Nh}_{-}^{-1}(20)$ is a present-oriented conversation to decide a course of action, whereas it is $10=t^{-}$sa' $^{\prime} y$ draw-up a proactive and patient-centered intervention-planning to support acherence throughout the whole SLIT course. It is quite obvious that the detailed knowledge of patit ' $t$ '? needs (but also preferences, expectations and viewpoints) and the foreseeak ${ }^{\prime} n, 1$. rer actions with the duty of allergy service are the needed basis on which to build an operatiına, partnership and to develop an effective actionplan aimed to improve adherence.

Improving patient's literacy on AIT and a Ilergy disease is the first step of SDM. A meta-analysis of published studies demonstrates the $k$ osit ve impact of health literacy on adherence and the efficacy of health literacy interver ir,n... (21) Health literacy can be defined as the capacity to obtain, understand and use $n \in$. ded information on disease and therapeutic options to make proper decisions. For this p. rpo: e, patients' education cannot be limited to the necessary,

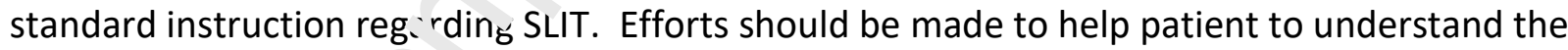
concept of desensitiza tion and the rationale, objectives and expected outcomes of SLIT. SLIT is not a relief medication :ut a long-term therapy normally given in addition to drugs and other prescriptions anc' itc results are not expected in a short time. For this reason, AIT should be proposed as i.e main therapy of allergy disease, rather than of symptoms. If benefits are not well perce $: a \mathrm{k}$ at ents may believe that allergy vaccines are ineffective and therefore unnecessary. Pa:.. t's $^{+}$nerception of inefficacy or poor efficacy is reported in literature as one of the main causes of SLIT withdrawal. $(6,22)$ Allergists should-careful avoid that the patients get unrealistic expectations. During the consultation allergist should highlight scientific evidence on SLIT efficacy 
and safety, and leverage effect on disease progression without giving too much emphasis on the expected symptoms' reduction. The notion that the results are not expected in a short time should be stressed and the prosecution of SLIT for at least one year encouraged even if ber efi. are not perceived by the patient. Communicate and let them understanding these poin $s$ is especially important for patients with allergic rhinitis, who (unlike patients with astı na, re less prone to a long-term, non-symptomatic therapy. Allergists should strive to persu ic'e 'he patients eligible for SLIT that allergic rhinitis is a chronic, not trivial disease and that alle gy I nmunotherapy is a keystone of therapy and prevention of its complications. (23)

A strong motivation of patient and a firm involvement of patients on ther $\mathrm{c}^{n}{ }^{n}$ atic program is essential to ensure adherence to vaccine immunotherapy. Studies on $n s$,-term adherence to SLIT

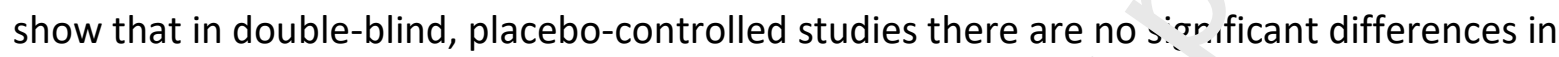
withdrawal rates between active and placebo groups. These finc"ings indicate that adherence, compared to perception of poor efficacy of therapy (very lik $\mathrm{k}^{\prime} \mathrm{V} v=$ nong placebo-treated patients) or other causes, depends above all on patients' motiv ${ }^{+i o n}$, that is the decision to participate in the trial and fulfil their commitments with the researc, or. (6)

A strength of our strategy to improve adherenc 2 r. th 2 group sessions. (Fig 1) Patients are recalled before starting immunotherapy for ec uca 'ional group session aimed to reassume fundamentals previously given individually $\mathrm{o}$ टาcı, one, to promote interactive discussion and to reinforce motivation and commitment. ' Juring these educational sessions allergists and nurses give practical illustrations on SLIT anc trai i the patients and parents to self-management. At the group sessions patients we e dquin reassured about at home regimen safety. Usual adverse reactions were explained in $d t$. .il and patients carefully instructed on prevention and selfmedication, but also on wh. th y should to do in case of more serious events or emergencies. The safety profile of SLIT is ve.y good and side-effects uncommon. In our experience however, emphasizing safety b€ 'on / measure is something wrong. Perception of side-effects greatly differs in relation with the. o o $\mathrm{n}$ literacy, psychology and abstract representation of the symptoms and their possible cu. se quences. (14) Patients' concerns about adverse events perceived as potential harmful shou ${ }^{-1}$ be addressed via direct counselling and, were appropriate, by medical exam: ᄀtıo 1. $n$ fact, as ranked by $66 \%$ of practicing allergists, tolerability proves to be the second or ...- 1 ( 7use by importance order of SLIT withdrawal. (22) SLIT should be compared to a welltolerated drug therapy not always devoid of adverse events. 
There are enough evidences in literature that regular monitoring visits can improve long-term SLIT adherence. $(6,24-26)$ Periodical controls provide the opportunity for communication and interaction with allergy team, and can be a way to strengthen patient's motivation and his' her proactive involvement on therapeutic program.

The general plan of management and supervision of SLIT and allergy disease was dis iISs $d$ once again during the group session. The utility of periodic medical-controls and exami in cll. ns was stressed, emphasizing the mutual interest for both patients and physicians on i ggu ar and wellplanned follow-up to ensure safety and optimal disease control grading drue : herapy. Estimate

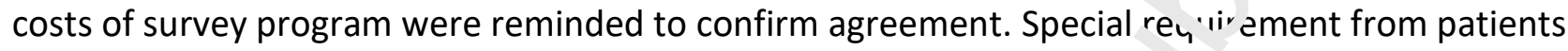
were considered during the group session to show how they could be $1_{1}^{\text {t }}$ g grated into routine activities.

Waste of time proves to be one of the major concerns for the $\mathrm{p}_{c}{ }^{+}$ients on SLIT. Even the distance from the allergy office seems to be a problem, as a chang ${ }^{\circ} 0$. wr $\mathrm{rk}$ residence demonstrates to be a significant cause of SLIT withdrawal in the present stu ' 'v.

The organization of allergy unit to meet patients' neec - ar d avoid any undue waste of time was explained. Detailed instructions were given to $p^{\sim} v_{v}$ it ong wait for bureaucratic procedures and reservation lists, current problems with hospit al c. II-center and trouble to make contact with allergy unit staff. The possibility of admitte $n r \_u_{1}$. ing shift change or lunch break was provided for employees how had had difficulty in sbtz ining work permits. Ongoing assistance and counseling service by allergy unit tea. n, ai ;o by phone, and the possibility of direct access to medical controls and examination ; $N_{i} j$ assured. But at the same time the regulations of the National Health System and de -ies of resident health services were reminded in order to clearly define the rules to which $b c h \mathrm{~h}$ !althcare providers and patients have to conform. 


\section{CONCLUSIONS}

There is no doubt that an accurate knowledge of patit ?t-related factor is essential for the development of an effective action-plan to improve acher ance.

Of course, patient-related factors are not the or ' $i$. stf iminants adherence. This is influenced by several other factors, which include social-eco 10, ic issue, health care system, relationship with medical team, and the characteristics of th $\leq r_{\imath} \leqslant e_{-} \_$and related therapy. Each region or local context may have its own specific chara teri tics. Nevertheless, there is unquestionable evidence that most barriers to "at-home thera, 'y lo $1 g$-term adherence" are fundamentally the same for different settings and pathologies, a 1 . ast in western countries with high socio-economic development. As a matter ot ' 'ct, our results are overall consistent with the remarks of most studies and systematic revi $v s$ ( $\mathrm{n}$ barriers to medication long-term adherence.

In the present study a pi ractıve management of SLIT starting from SDM process has been applied and tested in the daily clin cal practice. SLIT adherence can only be successful if there is an effective cooperatiu $1 \mathrm{r}$ stween the patience and health-care provider. The study proves SLIT adherence is an "sx Jeriences" that should be supported throughout the whole duration by active, ongoing inter : antions able to meet patients' needs, preferences and expectations.

The ir srve ot on strategies here explained are more easily applicable to hospital outpatients clir. $.2, r$, it we have to stress the concept that they may constitute a kind of guide-line applicable in greater or lesser extent to any setting where you can manage allergy immunotherapy. 
Of course, SDM process and the other proactive interventions here described seem timeconsuming. They might appear too burdensome in term of a lot of work to do, personal commitment, reorganization of processes and working methodologies, and whatever else However, the fundamental principles of healthcare management teach that to put user an' ' their needs and expectations at the centre of the healthcare process, is the path to impri ' $t_{1}$ ? service's performances and effectiveness. Once the scenario is well-defined, the ic it . Its' priorities are well established, and the diagnostic and therapeutic care patr'wa.'s cr nveniently organized, the timeliness in the problems solving and the service's flexibilitv in term of ability to adapt quickly to changes of needs and context) improve. Despite the iscut 'isruption, waste of time and human and material resources that a disappointed and non-c $m$ pliant patient can cause, the reorganization of outpatient facilities, as here suggested, result : "money and time saving". Anyway, to assure good SLIT adherence appears to be a worldw. 'te priority: for patients, allergists and allergy vaccines manufacturers. Adherence gets wo ‘? ve time, and withdrawal rate appears really impressive at third year of therapy. (6, 27-29) Non-adherence and untimely discontinuation jeopardize efficacy, discredit and cast ' 'n' Jts about the genuine useful of a therapy whose benefits are not instant and neith $2 r$ ×x ected in the short-time. In spite of the progress on vaccine manufacturing and the scieni fic evidences of efficacy produced by clinical trials, doubts affect not only non-complian' $p_{t} t^{t} e_{1}$ 's, but also a consistent number of family physicians and non-allergy specialists. $U$ Ider standing and overcoming the many barriers that can hinder adherence is the only way to $\epsilon$ nsu, e the effectiveness and the expected results of SLIT.

ACKNOWLEDGMENTS: Special tanks to Mrs. Rossana Baioni, RN, for her valuable help with interviews and helping understanding patients' needs, preferences and requests. The success in terms of adherence 
of our management strategy of allergy immunotherapy strongly depended on her valuable work as head nurse of the allergy hospital outpatient clinic.

CONFLICT OF INTEREST: The author has no conflicts of interest to declare.

FUNDING SOURCE: None

\section{REFERENCES}

1. Shamji MH, Durham SR. Mechanisms of allerg ^n immunotherapy for inhaled allergens and predictive biomarkers. J Allergy Clin Immunol . 01 ; 140: 1485-98

2. Cohn JR, Pizzi A. Determinants of patient a r.ıp iance with allergen immunotherapy. J Allergy Clin Immunol 1993; 91: 734-73;.

3. Lower T, Henry J, Mandic L, Janosk' J Frri'?y GA Jr. Compliance with allergen immunotherapy. Ann Allergy 19'3; 7U: 480-482.

4. Hankin CS, Cox L, Lang D et a . Al! ’rgy immunotherapy among Medicaid-enrolled children with allergic rhinitis: patter $r$, f care, resource use, and costs. J Allergy Clin Immunol 2008; 121: 227-232.

5. Canonica GW, Cox ', Pa vankar R et al. Sublingual immunotherapy. World Allergy Organization Po tioı. Paper. Update 2013. World Allergy Organ J 2014; 7:6. Available at: http://www.v aoji urnal.org/content/7/1/6

6. Antico A. L -..g term adherence to sublingual therapy: literature review and suggestions for mar. ' oelrient strategies based on patients' needs and preferences. Clin Exp Allergy 2014, 44: 1314-26.

7 Vic rlc Health Organization. Adherence to long-term therapy. Evidence for action. ivailable at: http://www.who.int/chp/knowledge/publications/adherence_report/en/ 
8. Gellad WF, Grenard J, McGlynn EA. A review of barriers to medication adherence. A framework for driving policy options. RAND Corporation 2009. Available at: http://www.rand.org/content/dam/rand/pubs/technical_reports/2009/RAND_TR 65. .df.

9. Chesanow N. Why Are So Many Patients Noncopliant? Medscape Jan 16, 2014. Ivai able at: hppt://www, medscape,com/viewarticle/818850.

10. Elwyn G, Frosch D, Thomson R, Joseph-Williams N, Lloyd A et al. Shared d scisı .n making: a model for clinical practice. J Gen Intern Med 2012; 27: 1361-1367.

11. Joseph-Williams N, Lloyd A, Edward A, Stobbart L, Thomson D et al. inpiementing shared decision making in the NHS: lesson from MAGIC program. BMJ $>: 7 \cdot 357$ : j1744. doi: 10.1136/bmj.j1744.

12. DiMatteo MR, Haskard KB, Williams SL. Health beliefs, dise $-\circ$ severity, and patient adherence. A meta-analysis. Medical Care 2007; 45: 5८: 528

13. Stone B, Charap E, Black HL. Understanding Pati $\imath^{+} L$ ' $n f$; iences with Allergen Immunotherapy: Living with Allergies Study. K.`n Allergy Asthma Immunol. 2019: 123:110111, doi: 10.1016/j.anai.2019.03.009.

14. Horne R. Compliance, adherence and ccn $\_$d=nce. Implication for asthma treatment. Chest 2006; 130: 65S-72S.

15. Briesacher BA, Gurwitz JH, Soumer $₫ 1,2$ r , tients at-risk for cost-related medication nonadherence. A review of the liter itur $`$ J Gen Intern Med 2007; 22: 864-871.

16. Zivin K, Ratliff S, Heisler MM, '-anł a KM, Piette JD. Factors influencing cost-related nonadherence to medicat 011 . older adults: a conceptual based approach. Value Health 2010; 13: 338-345.

17. More DR, Hagan LL. Facl ors affecting compliance with allergen immunotherapy at a military medical enter. Ann Allergy Asthma Immunol 2002; 88: 391-394

18. Bell JS, Airaks, ven MS, Lyles A, Chen TF, Aslani P. Concordance in not synonymous with complianct ur ddherence. Br J Clin Pharmacol 2007; 64: 710-711

19. Cushing ? Metcalfe R. Optimizing medicines management: From compliance to concu-dance. Ther Clin Risk Manag 2007; 3: 1047-58.

$2^{r} \mathrm{NJ}+\mathrm{F}$ ngland. Shared Decision Making: Summary Guide. Available at: 1.tps://www.england.nhs. uk/publication/shared-decision-making-summary-guide/

21. Miller TA. Health literacy and adherence to medical treatment in chronic and acute illness: A meta-analysis. Patient Educ Couns. 2016; 99:1079-1086 
22. Scurati S, Frati F, Passalacqua G, Puccinelli P, Hilaire C, Incorvaia C. Adherence issues related to sublingual immunotherapy as perceived by allergists. Patient Prefer Adherence 2010; 4: 141-145.

23. Brożek JL, Bousquet J, Agache I et al. Allergic Rhinitis and its Impact on Asthma $(A R, A)$ guidelines-2016 revision. J Allergy Clin Immunol 2017; 140: 950-958

24. Vita D, Caminiti L, Ruggeri P, Pajno GB. Sublingual immunotherapy: adher ㄹ $c \in$ based on timing and monitoring control visits. Allergy 2010; 65: 668-669.

25. Incorvaia C, Rapetti A, Scurati S, Puccinelli P, Capecce M, Frati F. Imb -tance of patient's education in favouring compliance with sublingual immunotherap; '.llergy 2010; 65: 1341-1342.

26. Savi E, Peveri S, Senna G, Passalacqua G. Causes of SLIT disc $n^{n+.}$ nuation and strategies to improve the adherence: a pragmatic approach. Allergv < 13; 68: 1193-1195.

27. Senna G, Lombardi C, Canonica GW, Passalacqua $\overbrace{\text {. I I ' }}$ ' adherent to sublingual immunotherapy prescriptions are patients? Tí. o manufacturers' viewpoint. J Allergy Clin Immunol 2010; 126: 668-669.

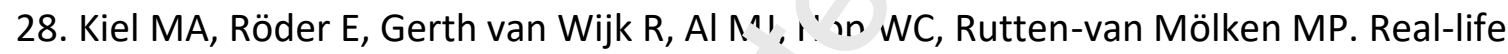
compliance and persistence among us srs if subcutaneous and sublingual allergen immunotherapy. J Allergy Clin Imm ur J' «i13; 132: 353-60.

29. Vogelberg C, Brüggenjürgen B, 'ich`er $H$, Jutel M. Real world adherence and evidence of subcutaneous and sublingual imn unotherapy in grass and tree pollen-induced allergic rhinitis and asthma. Patie t $\mathrm{tr}$-ference and Adherence 2020; 14: 817-827 


\section{FIGURE LEGENDS}

Fig. 1 - Action plan conceptual framew srk. steps and recap of key-points.

Fig. 2 - Patients' assessment by \isua analogical scale of the relevance of some factors influencing SLIT adherence.

(See text for further explana ic . . $\bullet-\bullet$ : minimum and maximum value assigned by the patients. $\mathbf{X}$ : value ascior ${ }^{\prime}$ by more than $75 \%$ of the patients.) 